\title{
Coupled Sharp-interface and Density Dependent Model for Simultaneous Optimization of Production Well Locations and Pumping in Coastal Aquifer
}

Subhajit Dey ( $\square$ sri.pce15@iitp.ac.in )

Indian Institute of Technology Patna https://orcid.org/0000-0002-2457-0572

Om Prakash

Indian Institute of Technology Patna

\section{Research Article}

Keywords: saltwater intrusion, groundwater management, pumping location optimization, Puri city

Posted Date: January 17th, 2022

DOI: https://doi.org/10.21203/rs.3.rs-1012819/v1

License: (c) (1) This work is licensed under a Creative Commons Attribution 4.0 International License.

Read Full License

Version of Record: A version of this preprint was published at Water Resources Management on April 13th, 2022. See the published version at https://doi.org/10.1007/s11269-022-03145-w. 


\title{
Coupled sharp-interface and density dependent model for simultaneous optimization of production well locations and pumping in coastal aquifer
}

\author{
Subhajit Dey* \\ ORCID: 0000-0002-2457-0572 \\ $\mathrm{PhD}$. Scholar, \\ Department of Civil and Environmental Engineering, \\ Indian Institute of Technology Patna, Bihta, Bihar 801106, India. \\ sri.pce15@iitp.ac.in \\ +916115233159
}

Om Prakash

Assistant Professor,

Department of Civil and Environmental Engineering, Indian Institute of Technology Patna, Bihta, Bihar 801106, India. om.prakash@iitp.ac.in

+9106115-233193

\section{*Corresponding author}

\begin{abstract}
The main management challenge in coastal aquifers is to prevent saltwater intrusion, still ensuring ample supply of freshwater. Saltwater intrusion happens due to unregulated pumping from production wells. Therefore, it is essential to have effective management policy, which ensures the requisite amount of freshwater to be withdrawn from coastal aquifers without causing saltwater intrusion. To achieve these conflicting objectives, a methodology for optimizing production well locations and maximizing pumping from production wells is presented. Location of pumping wells directly affects the amount of freshwater that can be pumped out of costal aquifer. Simultaneous optimization of production well locations and pumping from the same is achieved by linking mathematical simulation models with optimization algorithm. A new methodology using coupled sharp-interface and density dependent simulation models is developed to find optimal well locations and optimize the amount of freshwater pumped from the coastal aquifer. The sharp-interface model is linked with Simulated Annealing to solve this constrained optimization problem. In the next step, density dependent model is used to improve the outcome of sharp-interface model. The process is iterated until the results of the sharp-interface mimic the results of density dependent model which is more realistic, as it considers both advection and dispersion phenomenon. The performance of the developed methodology is evaluated for saltwater intrusion in coastal city of Puri, India. The performance evaluation results show the applicability of the developed methodology for management of saltwater intrusion while maximizing freshwater pumping in coastal aquifers under constraints of well location.
\end{abstract}

Keywords: saltwater intrusion, groundwater management, pumping location optimization, Puri city 
Statements and Declarations: This research is a is part of Computational Fluid Lab of Indian Institute of Technology Patna which is funded by Ministry of Human Resource and Development (MHRD), Govt. India. We thank Dr. Himanshu Joshi of Indian Institute of Technology Roorkee providing relevant data for the Puri city. The used data for this article, can be accessed from article and referenced text. Other data can be available on request. 


\section{Introduction}

Throughout the world, coastal areas have been at the forefront of development activities due to its direct access to global trade route via sea. This has led to large cities coming up along the shorelines over a period of time, with a thriving population. Large amount of freshwater is required for sustaining this thriving population, which is met from pumping of groundwater from coastal aquifers. The reliance on groundwater continues to grow due to increase in uncertainties surrounding reliable quantity of quality surface water. These coastal groundwater aquifers are often overexploited to meet the increasing demand. Due to overexploitation of groundwater resources, water table depletes disturbing the delicate balance between the freshwater and the saline seawater. Falling groundwater table results in the reversal of groundwater flow allowing saline seawater to occupy the space of freshwater. This phenomenon is called saltwater intrusion. Once saltwater intrudes into a coastal freshwater aquifer, reclamation of such aquifers is economically imprudent (Frind 1982; Park and Aral 2004). Therefore, it is essential to develop a sustainable management policy for preventing saltwater intrusion in coastal aquifers and still meet the freshwater demand of the coastal cities that depend on it. Thus, the main objective of coastal aquifer management is to pump requisite amount of freshwater without causing saltwater intrusion. The above objective can be achieved by simultaneous re-orientation of production well locations and pumping optimization (Dey and Prakash 2019b; Todd 1959). This study presents a simulation optimization based methodology for simultaneously optimizing these competing objectives.

Optimally regulating freshwater pumping from existing production wells for management of saltwater intrusion is well documented. Various optimization algorithms ranging from linear programming (Culver and Shoemaker 1993; Das and Datta 1999) to heuristic optimization techniques such as genetic algorithm (Abd-Elhamid and Javadi 2011; Cheng et al. 2000), quadratic programming (Willis and Finney 1988), non-shorting genetic algorithm-II (Dhar and Datta 2009b), evolutionary annealing simplex (Kourakos and Mantoglou 2009) have been used in coastal aquifers for pumping optimization. It is also well established that varying combinations of production well locations with explicit pumping produce diverse saltwater responses (Guan and Aral 1999). Therefore, it is not just the amount of pumping but also the location of the production well needs to be optimally determined to realize greater freshwater production without causing saltwater intrusion. Determining the optimal locations of production wells becomes even more important when planning a new well field or adding more wells to existing well field in order to increase freshwater output and control saltwater intrusion. Thus, production well locations should be treated as an explicit decision variable in management of saltwater intrusion. Not much work has been reported wherein production well locations and pumping from these production wells have been simultaneously optimized for management of saltwater intrusion. This study tries to address this specific gap.

The use of simulation-optimization approach for finding optimal pumping in saltwater intrusion problem has been documented by various authors (Mantoglou and Papantoniou 2008; Park and Aral 2004). The problem is often solved as a constrain optimization problem with an objective of maximizing freshwater pumping, such that the pumping rates are within the subscribed limits and the salt concentration near the well locations (Abd-Elaty et al. 2021; Bhattacharjya and Datta 2005; Sreekanth and Datta 2011; Sreekanth and Datta 2014) or toe of the interface (Mantoglou 2003; Mantoglou and Papantoniou 2008) do not exceed the prescribed limits. The main benefit of such a simulation-based optimization technique is that the effect of any pumping strategy on saltwater intrusion can be realized by the simulation model. However, when the production well location is considered as an explicit decision variable along with pumping, realizing the effect of both in terms of saltwater intrusion using simulation model become computationally challenging. There could be millions of combinations of production well locations and candidate pumping value that needs to be simulated. 
Candidate solutions are simulated using simulation models and optimization model evaluates the optimality of the decision variables i.e. production well location and pumping rates. Among various simulation models, density dependent models incorporate the effects of dispersion and diffusion to simulate salt concentration (Abarca et al. 2007; Dausman et al. 2010; Dokou and Karatzas 2012; Willis and Finney 1988). Sharp-interface simulation models are based on Ghyben-Herzberg principal that discount the effects of dispersion and diffusion, making it easy to solve. This has been extensively used by Mantoglou and Papantoniou (2008) and Mantoglou et al. (2004). The density dependent model is computationally expensive (Dhar and Datta 2009a), whereas sharp-interface models lack in prediction accuracy (Dausman et al. 2010). To overcome difficulties in simulation models, surrogate models are often used in place of simulation models. Artificial Neural Network (Bhattacharjya and Datta 2009; Rao et al. 2003), Genetic Programing (Sreekanth and Datta 2010), Adaptive Neuro-Fuzzy Inference System (Roy and Datta 2018) are some of the common examples of use of surrogates for management of saltwater intrusion. Surrogate models require large datasets for training and validation of the model (Werner et al. 2013). In most practical scenarios of saltwater intrusion, such large datasets are seldom available. Therefore, problem becomes more difficult when pumping locations along with pumping are regarded as explicit decision variable.

To address these challenges, a new method based on combined use of sharp-interface model and density dependent model is developed (Christelis and Mantoglou 2016) for simultaneous optimization of production well locations and pumping in coastal aquifer. Pumping rates from production well and the location of the production wells are considered as explicit decision variable to be optimally determined by the optimization model. Various factors in determining production well locations are, distance between the production wells, location of the wells from the aquifer boundary, safe distance from poor water quality zone, and intrusion of saltwater interface (Ahmadi et al. 2021). The optimization algorithm essentially tries to navigate efficiently through the space of feasible solutions to find the most optimal solution. In this method first sharp-interface model based on Strack (1976) potential is linked with Simulated Annealing (SA) (Goffe 1996) to find optimal pumping for varying well locations. Subsequently, density dependent simulation model (SEAWAT) (Guo and Langevin 2002) is linked with Particle Swarm Optimization (PSO) to adjust the outcomes of the sharp-interface model (Dey and Prakash 2020). This iterative process is continued until the total pumping of freshwater is maximized without causing saltwater intrusion at proposed production well locations optimally chosen by the methodology. Performance of the developed methodology is evaluated as a proof of concept for coastal aquifer of Puri city in India. The results indicate that, the combined use of sharp-interface model and density dependent model is viable alternative for simultaneous optimization of production well locations and pumping as a tool for managing saltwater intrusion.

\section{Methodology}


The main objective of the developed methodology is to maximize the freshwater pumping from optimally located production wells in a coastal aquifer such that it meets the freshwater demand without causing saltwater intrusion. Since, the location of the production wells in the aquifer has direct bearing on the amount of freshwater that can be pumped out of the aquifer, therefore, the locations of the production wells are treated as an explicit decision variable. The optimal values of the pumping rates and the optimal location of the wells are simultaneously estimated by the developed linked simulation-optimization model. A coupled sharp-interface and density dependent model is linked with SA and PSO respectively, to predict the optimal pumping rates and pumping locations such that saltwater intrusion can be managed without compromising on the demand for freshwater.

\subsection{Sharp-interface model}

The developed sharp-interface model is based on following considerations: (a) developed model follows Ghyben - Herzberg principal i.e. saltwater and freshwater are two immiscible liquids, therefore, a sharp-interface is present between them. (b) Dupuit's approximation is valid for the unconfined aquifer. Figure 1 shows a schematic sectional view of an unconfined coastal aquifer. As shown in figure 1, two zones are distinct based on the presence of the saltwater. In zone 1, only freshwater is present and in zone 2, both freshwater and saltwater are present separated by a sharp-interface.

The head of the water from datum is $h$, depth of freshwater below the water table is $b$, and $d$ is the height of mean sea level (MSL) from the datum. $\rho_{f}$ is the density of the freshwater and $\rho_{s}$ is the density of saltwater. Density ratio $\varepsilon$ is defined according to Ghyben-Herzberg as:

$\varepsilon=\frac{\rho_{\mathrm{s}}-\rho_{\mathrm{f}}}{\rho_{\mathrm{f}}}$

From, Ghyben-Herzberg observation, the relation between the height of freshwater above MSL $\left(h_{f}\right)$ and depth of freshwater below MSL $\left(h_{s}\right)$ for zone 2 is given by equation 2.1 and 2.2.

$\mathrm{h}_{\mathrm{f}}=\varepsilon \times \mathrm{h}_{\mathrm{S}}$

$\mathrm{h}-\mathrm{d}=\varepsilon \times \mathrm{h}_{\mathrm{s}}$

Strack (1976) and

Mantoglou et al. (2004) developed a differential equation based on a single potential which applies to both the zones for the unconfined aquifer, given by equation 3 .

$\frac{\partial}{\partial \mathrm{x}}\left(\mathrm{K} \frac{\partial \phi}{\partial \mathrm{x}}\right)$

$+\frac{\partial}{\partial y}\left(K \frac{\partial \phi}{\partial y}\right)+Q(x, y)$

$=0$

The potential for each zone-1 $\left(\phi_{1}\right)$ and for zone-2( $\left.\phi_{2}\right)$ is expressed as follows: 
$\phi_{1}=\frac{1}{2}\left[h^{2}-(1+\varepsilon) d^{2}\right]$

$\phi_{2}=\frac{1+\varepsilon}{\varepsilon}(\mathrm{h}-\mathrm{d})^{2}$

The potential at the location of the toe of interface $\left(\phi_{\tau}\right)$ is defined by equation 5 (Cheng et al. 2000; Mantoglou et al. 2004):

$\phi_{\tau}=\left[\frac{\varepsilon(\varepsilon+1)}{2}\right] \mathrm{d}^{2}$

MODFLOW-2000 (Harbaugh et al. 2000) is used to solve equation 3 and a Lagrangian interpolation method (equation 6) is used to calculate the toe location of interface with help of equation 5 .

$\phi_{\tau\left(x_{k}\right)}=\prod_{\mathrm{j}=0}^{\mathrm{n}}\left(\phi_{\tau}-\phi_{j}\right) \sum_{\mathrm{i}=0}^{\mathrm{n}} \frac{\phi_{i}\left(\mathrm{x}_{\mathrm{k}}\right)}{\left(\phi_{\tau}-\phi_{\mathrm{i}}\right) \prod_{\mathrm{j}=0, \mathrm{j} \neq \mathrm{i}}^{\mathrm{n}}\left(\phi_{\mathrm{i}}-\phi_{\mathrm{j}}\right)}$

Here, at $k^{\text {th }}$ row and $i^{\text {th }}$ column the potential is $\phi_{i}$ and the distance from the sea is $\phi_{i}\left(x_{k}\right), n$ is the total number of columns. For $j^{\text {th }}$ column potential is $\phi_{j}$. The toe of interface is $\phi_{\tau}$ and the corresponding location is $\phi_{\tau}\left(x_{k}\right)$.

\subsection{Density dependent model}

In an undisturbed coastal aquifer, a mixing zone is present between freshwater and saltwater. In this zone density of water gradually decreases from the density of saltwater to the density of the freshwater. This zone is created due to hydrodynamic dispersion. This conjugate flow (advection \& hydrodynamic dispersion) is expressed mathematically in form of a partial differential equation given by equation 7 (Guo and Langevin 2002):

$-\nabla \cdot(\rho \vec{q})+\bar{\rho} q_{s}=\rho S_{p} \frac{\partial P}{\partial t}+\theta \frac{\partial \rho}{\partial C} \frac{\partial C}{\partial t}$

where $\rho$ is the fluid density, $\vec{q}$ is the specific discharge vector, $\bar{\rho}$ is the fluid density entering or leaving the medium, $q_{s}$ is the volumetric flow rate at source or sink, $\theta$ is the porosity, $t$ is the time, $\mathrm{P}$ is the fluid pore pressure, $\mathrm{C}$ is the concentration of the solute and $S_{p}$ is the specific storage. Equation 7 is a combination of flow and transport equation linked by density term. There are various finite difference and finite element based methods to solve this equation. In this study finite difference based model SEAWAT (Guo and Langevin 2002) is used to solve equation 7. SEWAT uses flow model MODFLOW (Harbaugh et al. 2000) and transport model MT3DMS (Zheng and Wang 1999) together to solve the above equation.

\subsection{Formulation of pumping optimization problem}

The main objective is to maximize freshwater pumping for a given period without causing saltwater intrusion at the designed pumping well locations. To achieve this objective, both the locations of the pumping wells, and pumping rates form the designed wells are optimized. To achieve this sharp-interface simulation model is linked with SA optimization algorithm. The formulation of the optimization problem is discussed using the following equations: 
Maximize $Q_{\mathrm{t}}=\sum_{i=1}^{N} Q_{i}$

Subjected to: $d_{i}-d_{\tau i} \geq D$

$Q_{i}^{\text {Min }} \leq Q_{\mathrm{i}} \leq Q_{i}^{\text {Max }}$

$\left|\sqrt{\left(x_{i}-x_{i+1}\right)^{2}+\left(y_{i}-y_{i+1}\right)^{2}}\right|>2 D$

$x_{i}^{\min }<x_{i}<x_{i}^{\max }$

$y_{\mathrm{i}}^{\min }<\mathrm{y}_{\mathrm{i}}<\mathrm{y}_{\mathrm{i}}^{\max }$

where, $Q_{i}$ is the pumping from $\mathrm{i}^{\text {th }}$ well, $d_{i}$ is the distance of the well from coast, $d_{\tau i}$ is the distance of the toe of sharp-interface from the coast, $\mathrm{N}$ is the total number of wells, $\mathrm{x}_{\mathrm{i}}, \mathrm{y}_{\mathrm{i}}$ is the location of the $\mathrm{i}^{\text {th }}$ well, $\mathrm{x}_{\tau \mathrm{i}}$ location of the interface at the $\mathrm{x}^{\text {th }}$ row, $\mathrm{Q}_{\mathrm{i}}^{\mathrm{Min}}$ and $\mathrm{Q}_{\mathrm{i}}^{\mathrm{Max}}$ is the minimum and maximum allowable pumping from any $i^{\text {th }}$ well respectively. $\mathrm{D}$ is the minimum safe distance between toe of interface and location of well.

The freshwater pumping from the production well is maximized subject to the constraint set given by equation 8.2 , and 8.3 . Equation 8.2 essentially constrains the location of the saltwaterfreshwater front in such a way that it never crosses the pumping well location. This ensures that the salt water never reaches the production well, thus preventing saltwater intrusion.

Locations of the pumping wells $\mathrm{x}_{\mathrm{i}}, \mathrm{y}_{\mathrm{i}}$ is an explicit decision variable, which is optimized in order to maximize freshwater pumping. In order to decide the most optimal location of the pumping wells, it is to be ensured that the cone of depression of one pumping well does not interfere with that of another. Interference of cone of depressions of pumping wells reduces the yield rates from a well. Thus, a minimum limiting distance is maintained between two wells given by equation 8.4. This, constraint gives an added flexibility in deciding the well locations for different scenarios, i.e. maintaining minimum separation between the well and any restricted area where the well should not be installed.

Equation 8.5 ensures that the pumping wells are located within the boundary of the study area. Wells if located on the boundary of the study area may not be able to reach its full freshwater yield rates and overall reduce the freshwater production from the coastal aquifer. These added constraints given by equation 8.4 and 8.5 controls the location of the pumping wells such that the total production of freshwater from these pumping wells is maximized when solved in a sharpinterface and SA based linked-simulation optimization model.

\subsection{Simulated Annealing}

Simulated Anneling (SA), a metaheuristic optimization technique for determining a function's global optima, was introduced by Kirkpatrick (1984). The optimization method is analogously derived from the Annealing of metals refers to an analogy with thermodynamics, specifically with the way that metals cool and anneal. The material is heated above the 
recrystallization temperature during the annealing process. The material is then administered via controlled cooling, eventually lowering the material's energy to a lower state. This systematic cooling redistributes the crystals and eliminates metal dislocations. The annealing system can avoid local malformations (local minima) due to inherent random fluctuations in energy within the metal. This analogy is utilized in SA algorithm to identify global optima of an objective function.

The algorithm is similar to hill climbing, except that instead of choosing the best move, it selects a random one, such as random energy flactuation. The chosen move is always approved if it improves the solution. If not, then the algorithm selects a solution based on a probability smaller than one. It attempts to recover from any local optima in this manner. The probability is primarily determined by $\mathrm{T}$. $\mathrm{T}$ is very much like the annealing temperature. In a typical SA optimization, $\mathrm{T}$ starts high and gradually falls according to a temparature reduction factor. As $\mathrm{T}$ decreases, the algorithm is more likely to reject solutions that do not satisfy the constraints (Goffe 1996). Rao et al. (2003) and Rao et al. (2005) employed SA to solve the problem of saltwater intrusion (2004).

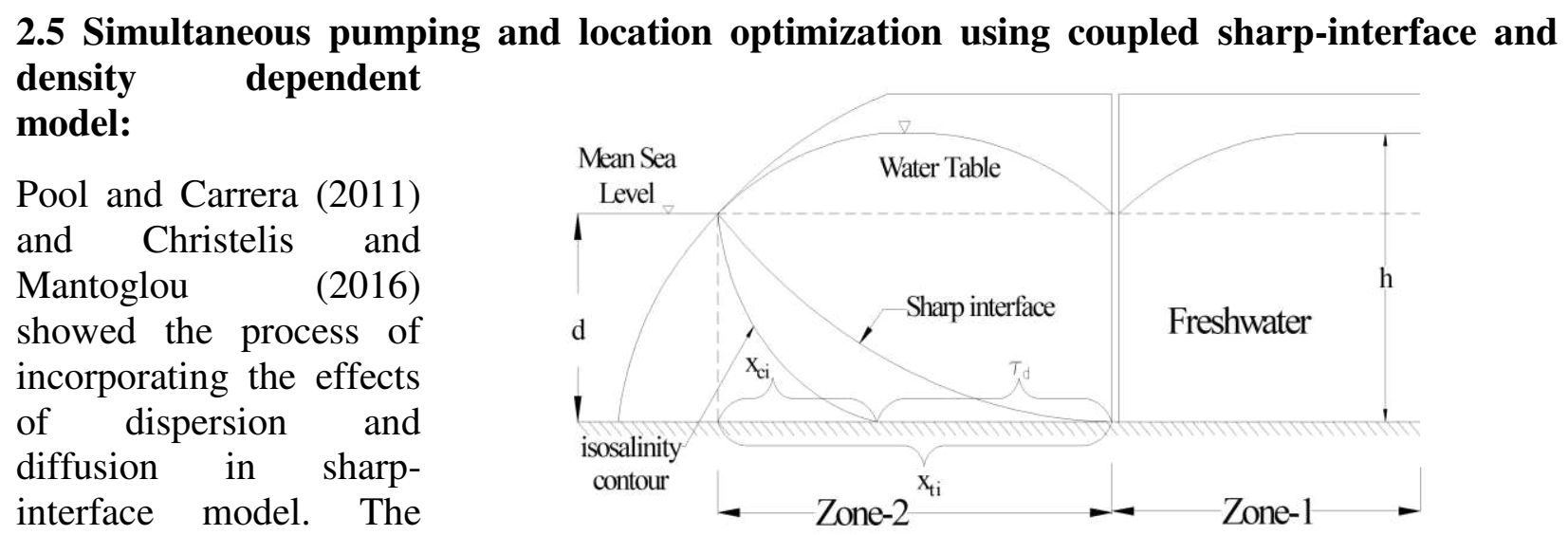

sharp-interface model is a function of head and density ratio. As the

Figure 2: Cross-section showing sharp interface and isosalinity freshwater head is contour

governed by pumping, therefore, density ratio can be modified such that sharp-interface matches the outcome of the density dependent model. On the basis of the above hypothesis, a methodology is developed where freshwater pumping is maximized by finding the optimal locations for installing pumping wells and estimating the optimal rate of pumping from the installed wells. Various candidate values of pumping locations and pumping rates are simulated in a sharp-interface simulation model linked to an SA optimization. These optimal values of pumping rates and pumping locations estimated by the sharp-interface is used as inputs to the SEWAT model to estimate the corresponding isosalinity contour. Now the difference between the obtained sharp-interface and the corresponding isosalinity contour is minimized by modifying the density ratio of sharp-interface model in an optimization framework. The density ratio is optimized such that the toe of sharp-interface and location of the toe of isosalinity contour closely match at the installed well locations (figure 2). The density optimization is given by equation 9.1 subject to constrain given in equation 9.2. The new density ratio value thus obtained is again passed on to the sharp-interface based linked simulation optimization model to 
improve the estimates of pumping rates and pumping well locations using the modified density ratio.

Minimize $\tau_{d}=\sum_{i=1}^{n}\left|\tau_{i}-c_{i}\right|$

Subjected to: $\quad 0 \leq \varepsilon \leq 0.035$

where $\tau_{i}$ is the distance of the toe location of sharp-interface from the coast at $\mathrm{i}^{\text {th }}$ well, $\mathrm{c}_{\mathrm{i}}$ is the distance of the toe location of isosalinity contour from the coast at the $\mathrm{i}^{\text {th }}$ well.

This iterative process continues until the pumping rates and pumping well locations obtained from the sharp-interface stabalizes and there is no significant change from one iteration to the other. This iterative use of coupled sharp-interface model and density dependent model is descibed through a schematic chart shown in figure 3.

In a classical
linked simulation
optimization the
simulation model (in
this case SEAWAT) is
iteratively evaluated
for each candidate
solution in order to
find the most optimal
pumping rates and the
pumping locations. As
density dependent
models are
computationally expensive, running several iterations of the same would make the solution

computationally

infeasible. In this developed

methodology the more precise SEWAT simulation model is replaced by a more efficient sharpinterface model. This efficiency is achieved at the cost of precision as sharp-interface models do not include

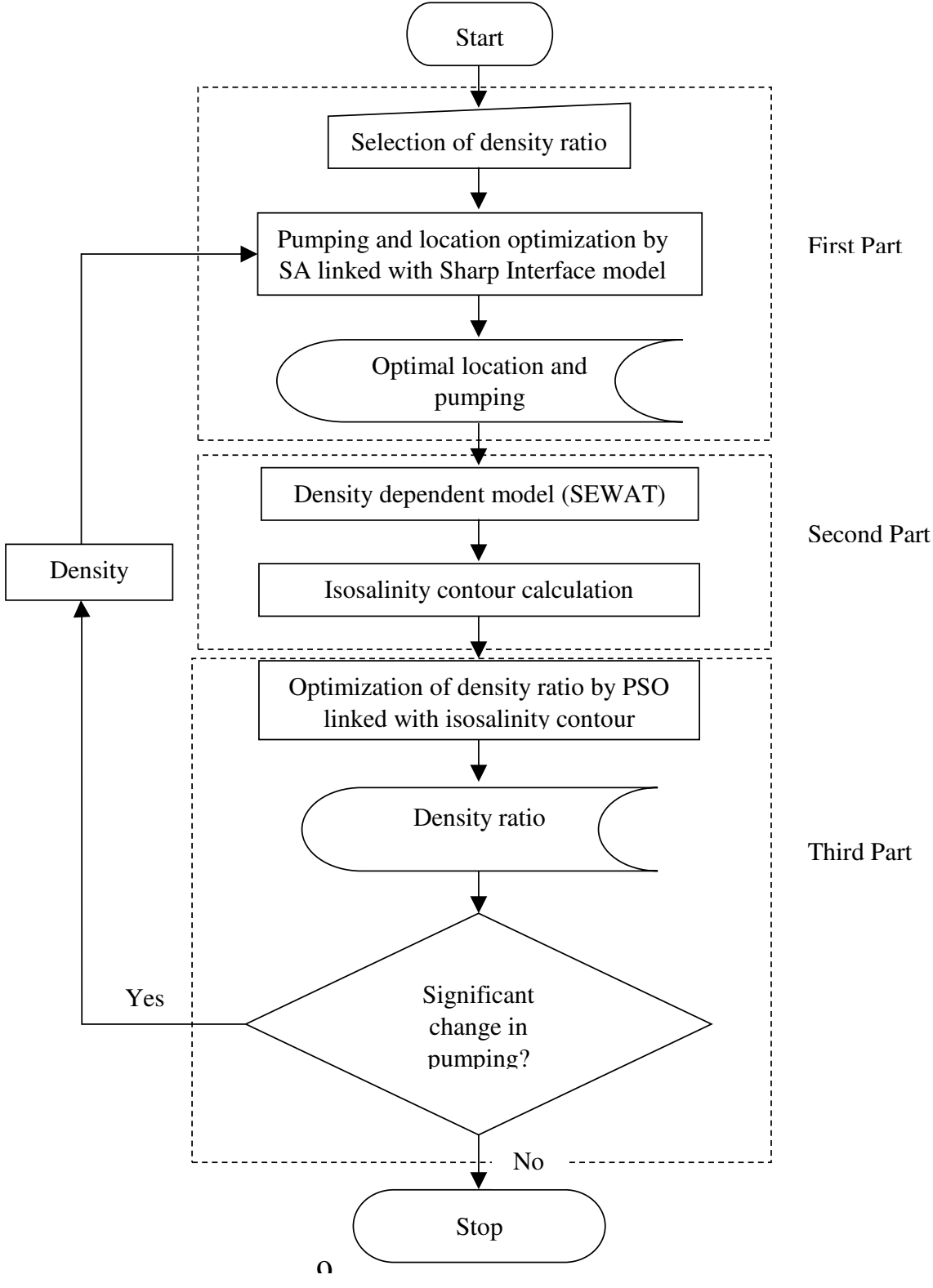

Figure 3: The developed iterative proses 
the effect of hydrodynamic dispersion. To compensate for this inaccuracy, the density ratio is adjusted until the toe location obtained by the sharp-interface model coincides with the toe location of the isosalinity contour of the SEWAT model. The specific advantage of this method is that it is no longer necessary to run the density dependent model iteratively but only once to estimate the isosalinity contour. Therefore, this method, in principle, decreases computing cost while generating results that are as accurate as a density dependent model.

\subsection{Particle Swarm Optimization}

In this study heuristic optimization, PSO has been chosen for linking the density dependent model. PSO's working principle is based on the movement of a flock of birds or a school of fish. The collective intelligence displayed by a flock of birds or a school of fish allows the group to seek food that would otherwise be unattainable if attempted by an individual. Thus, the strength in search for food essentially comes from sharing information gathered by each individual within the group. This concept is used in PSO to find an optimal pumping. PSO was introduced by Eberhart and Kennedy (1995). In this study, a modified version of PSO as proposed by Shi and Eberhart (1998) is used as an optimizer. In the used PSO algorithm, first $m$ number of particles are arbitrarily selected in defined search space. In second step, particles are evaluated for the objective function. In the final step, particles modify their location based on best objective function value governed by velocity $\left(v_{i}\right)$ of the particle (equation 10.1) (Poli et al. 2007). The velocity of each particle (equation 10.2) governs by constant inertia weight (w), cognitive constant $\left(c_{1}\right)$, social constant $\left(c_{2}\right)$, historical best location $\left(x_{g p}\right)$, best location of the particle for the current iteration $\left(x_{b p}\right)$, current location of the particle $\left(x_{i}\right)$ and a random number between 0 to1(r).

$x_{i+1}=x_{i}+v_{i+1}$

$v_{i+1}=w v_{i}+c_{1} r\left(x_{b p}-x_{i}\right)+c_{2} r\left(x_{g p}-x_{i}\right)$

Here, $\mathrm{w}$ is the percentage of velocity in $i^{\text {th }}$ iteration that should be retained for $(i+1)^{t h}$ iteration, $c_{1}$ and $c_{2}$ are acceleration or deceleration of the velocity based on difference of $x_{i}$ from $x_{g p}$ and $x_{b p} . \mathrm{r}$ is used to introduce the randomness in the direction of the movement.

\section{Performance evaluation of the developed methodology}

\subsection{Description of the hypothetical study area}

Two hypothetical study area (figure-4) are considers for evaluating the performance of the developed methodology. The study areas comprises of a heterogeneous, isotropic three

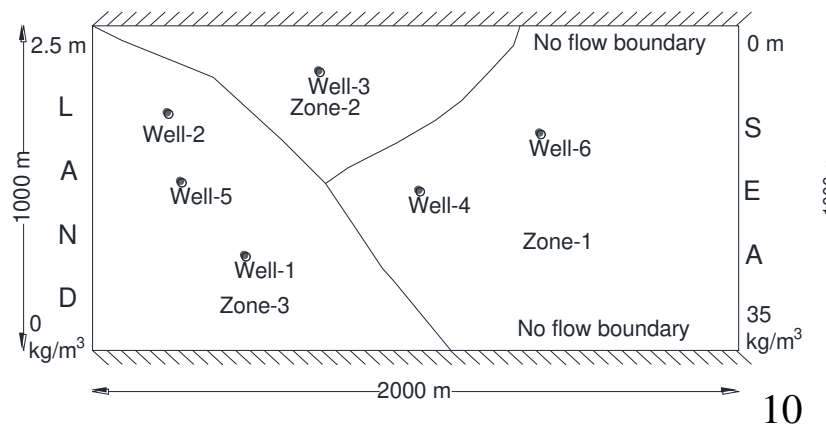

(a) Scenario-1

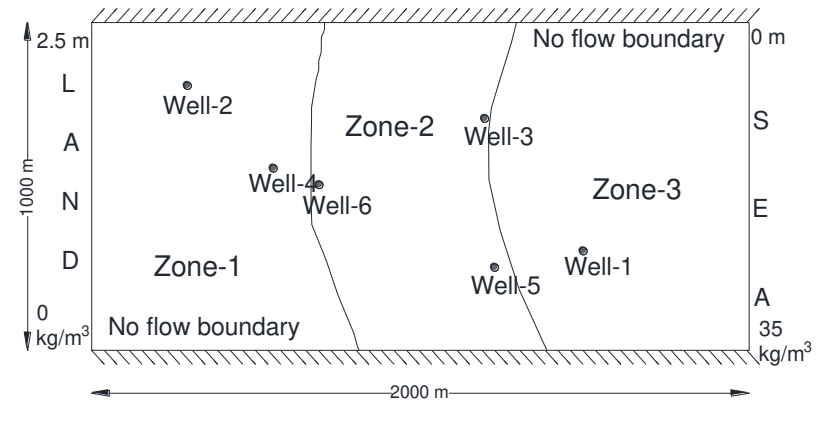

(b) Scenario-2

Figure 4: Plan view of hypothetical study area 
dimensional unconfined costal aquifer having an area of $2.0 \times 10^{6} \mathrm{~m}^{2}(1000 \mathrm{~m} \times 2000 \mathrm{~m} \times 15$ $\mathrm{m})$. The study areas are discretized into finite difference grids $(10 \mathrm{~m} \times 10 \mathrm{~m} \times 3 \mathrm{~m})$. The right side boundary is considered as the sea. The left hand boundary is land and considers as $2.5 \mathrm{~m}$ fixed head boundary.Therefore, at the start the head is considered lineally varying from land surface at $2.5 \mathrm{~m}$ to the seaside at $0 \mathrm{~m}$. The remaining two boundaries were considers as no-flow boundary. Therefore, two flow boundaries are taken i.e. the left and right side which are taken as a Dirichlet condition. Initially, the salt concentration in the aquifer is assumed to be zero. Dirichlet boundary condition is assigned at seaside and landside with concentration $0 \mathrm{~kg} / \mathrm{m}^{3}$ and $35 \mathrm{~kg} / \mathrm{m}^{3}$. It is assumed that the aquifer is pumped uniformly throughout the depth of the aquifer at the designed well locations. The aquifer is studied for a period of 10 years. The other hydrogeological parameters used in the model are presented in table-1.

Table 1: Hydraulic properties of hypothetical scenarios

\begin{tabular}{|c|c|c|c|}
\hline \multicolumn{2}{|l|}{ Parameter } & Scenario -1 & Scenario -2 \\
\hline \multicolumn{2}{|l|}{ Area of the aquifer } & $2 \mathrm{~km}^{2}$ & $2 \mathrm{~km}^{2}$ \\
\hline \multicolumn{2}{|l|}{ Grid dimension $(\Delta \mathrm{x}, \Delta \mathrm{y})$} & $10 \mathrm{~m} \times 10 \mathrm{~m}$ & $10 \mathrm{~m} \times 10 \mathrm{~m}$ \\
\hline \multicolumn{2}{|l|}{ Specific Storage } & $2.9 \times 10^{-3}$ & $2.9 \times 10^{-3}$ \\
\hline \multicolumn{2}{|l|}{ Specific Yield } & $30 \%$ & $30 \%$ \\
\hline \multicolumn{2}{|l|}{ Recharge rate } & $0.000222 \mathrm{~m} /$ day & $0.000222 \mathrm{~m} / \mathrm{day}$ \\
\hline \multicolumn{2}{|c|}{ Salt concentration in seawater } & $35 \mathrm{~kg} / \mathrm{m}^{3}$ & $35 \mathrm{~kg} / \mathrm{m}^{3}$ \\
\hline \multicolumn{2}{|c|}{ Longitudinal dispersivity $\left(\alpha_{t}\right)$} & $4.5 \mathrm{~m}$ & $4.5 \mathrm{~m}$ \\
\hline \multicolumn{2}{|l|}{$\alpha_{h} / \alpha_{t}$ and $\alpha_{v} / \alpha_{t}$} & 1 & 1 \\
\hline \multicolumn{2}{|l|}{ Study period length } & 30 years 9 months & 30 years 9 months \\
\hline \multirow{3}{*}{ Hydraulic conductivity } & Zone-1 & $18 \mathrm{~m} /$ day & $10 \mathrm{~m} /$ day \\
\hline & Zone-2 & $15 \mathrm{~m} /$ day & $15 \mathrm{~m} /$ day \\
\hline & Zone-3 & $16 \mathrm{~m} /$ day & $18 \mathrm{~m} /$ day \\
\hline
\end{tabular}

In the two hyothetical study scenarios considered, six number of pumping well needs to be installed for pumping freshwater. The locations of the pumping wells along with the pumping rates will be optimally obtained from the methodology. It is assumed that the installed wells will be uniformly pumped throughout the stress period. The upper and lower limit of the pumping is considered as $1000 \mathrm{~m}^{3} /$ day to $50 \mathrm{~m}^{3} /$ day respectively, for each well. To ensure that the installed well do not interfere with each other and contribute to its full potential a minimum distance of $350 \mathrm{~m}$ is kept between two wells and the wells are $350 \mathrm{~m}$ from the boundary.

\subsection{Description of coastal aquifer of Puri city}

Puri city is situated at the east coast of India spread between $19^{\circ} 47^{\prime}$ to $19^{\circ} 50^{\prime} \mathrm{N}$ latitudes and $85^{\circ} 48^{\prime}$ to $85^{\circ} 52^{\prime}$ E longitudes (figure 5) and has hot humid climate(Vijay et al. 2011a). The topography of the area slopes gently towards the sea. The maximum height at the north eastern side is $18.4 \mathrm{~m}$. The aquifer is sandy unconfind and extends below $40 \mathrm{~m}$ form Mean Sea Level (MSL). Puri city receives an average of $1,517 \mathrm{~mm}$ precipitation annuly. Most of the preciptation happens in the four months of monsoon (July to September) (Vijay et al. 2011a). Groundwater is the main source of freshwater for Puri city because rivers near the city are intermitent in nature and not able to supply required amount of freshwater. Finite difference model MODFLOW (Harbaugh et al. 2000) is used to simulate the flow model and SEAWAT (Guo and Langevin 2002) is used to calculte salt concentration. 


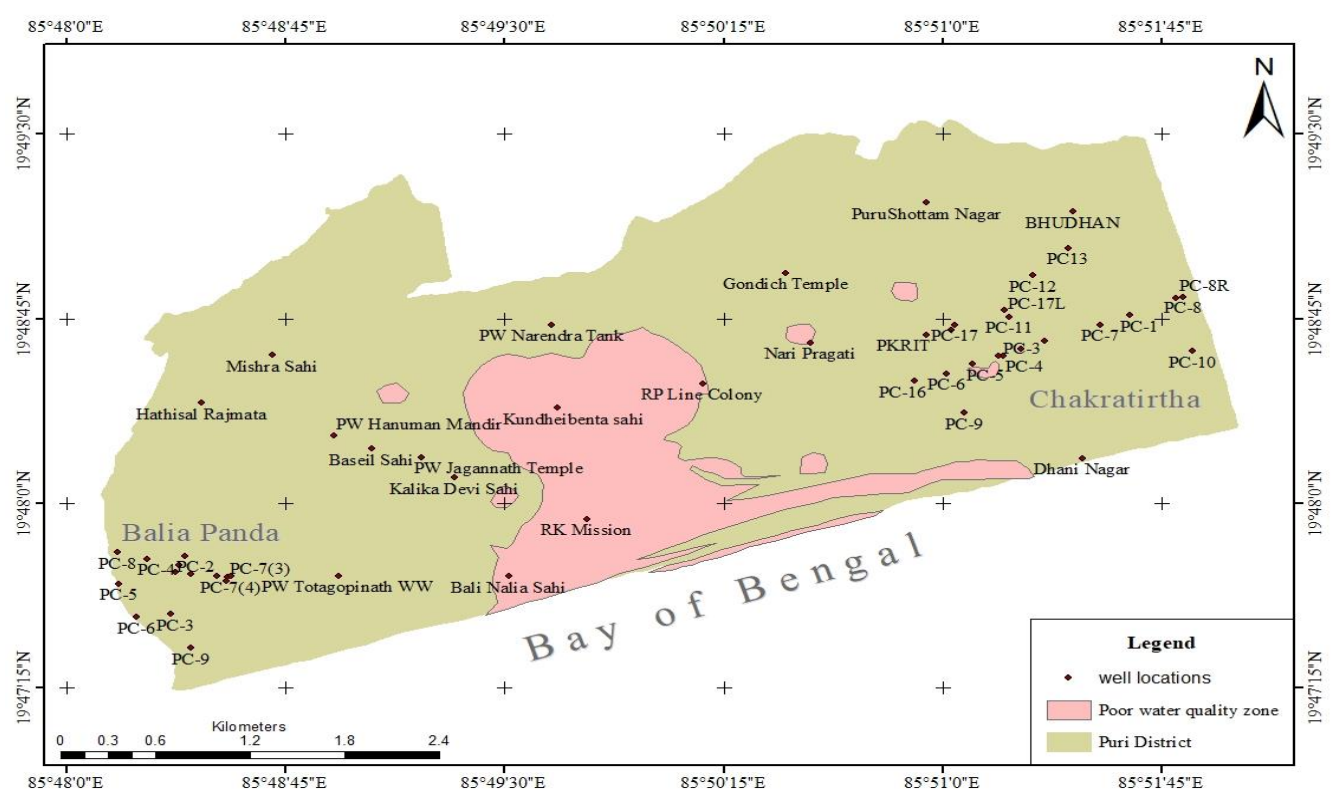

Figure 5: Location of pumping wells and poor water quality zone

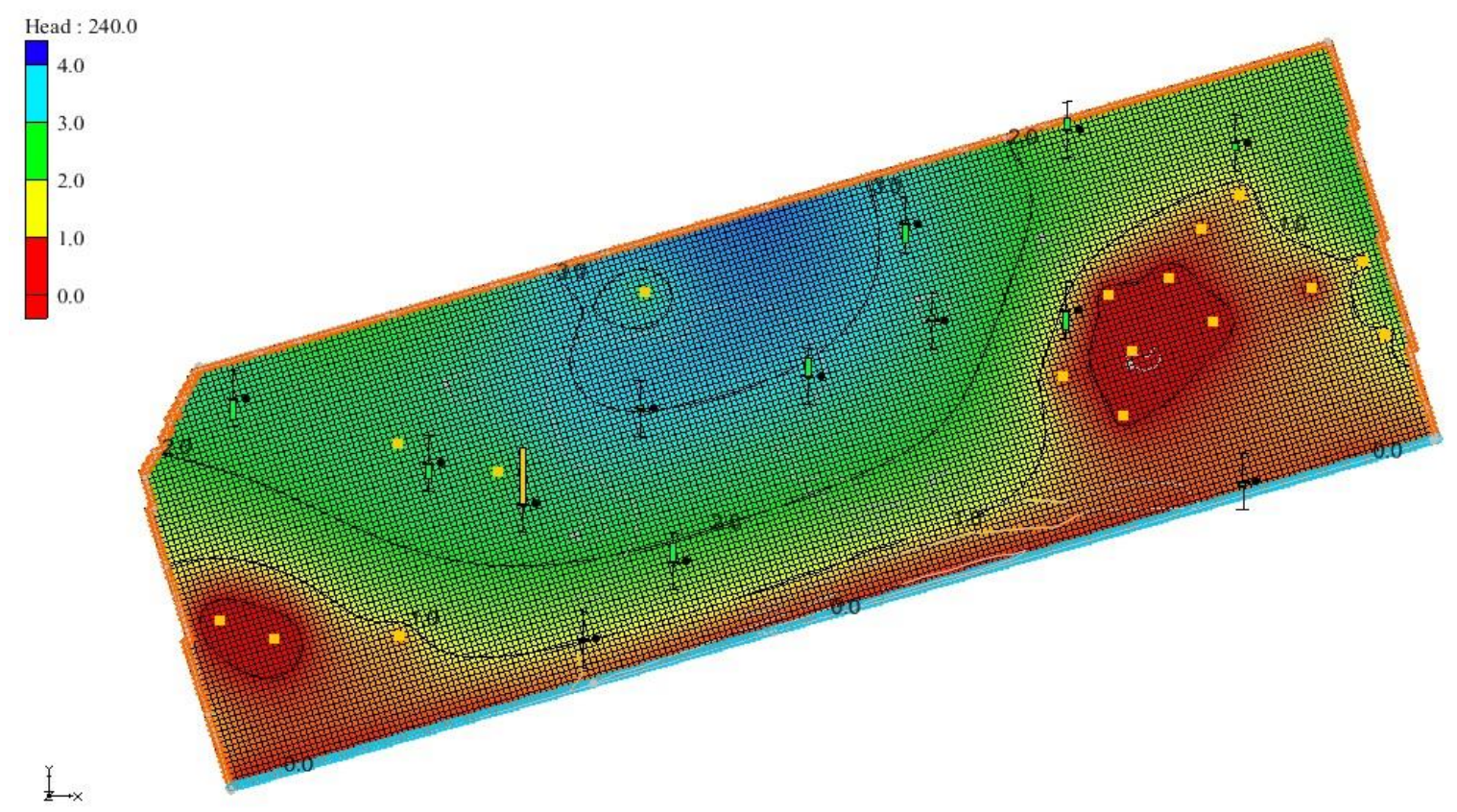

Figure 6: Calibrated flow model of coastal aquifer under Puri city

The city is supplied with $20.5 \times 10^{3} \mathrm{~m}^{3} /$ day through 36 pumping wells (figure-5). There are two pumping field in the city i.e. Chakratirtha and Balia Panda. There are 19 pumping wells in Chakratirtha and 13 wells in Balia Panda water field. There also four wells spread across the city. Apart from the pumping wells, there are several hand pumps. The aquifer is divided with $30 \mathrm{~m} \times$ $30 \mathrm{~m}$ finite difference grid with single layer. A fixed head value of $0 \mathrm{~m}$ and constant salt concentration of $35 \mathrm{~kg} / \mathrm{m}^{3}$ is taken along the coast. For the landside, the constant salt concentration of $0 \mathrm{~kg} / \mathrm{m}^{3}$ is taken. The head at the boundary is determined based on the contour 
from water table during post-monsoon of 2006 and pre-monsoon of 2007 provided by Vijay and Mohapatra (2016). Though, there are 19 production wells in Chakratirtha water field and 13 production wells in Balia Panda water field, only eleven production wells in Chakratirtha water field and a three pumping well in Balia Panda water field are considered in the finite difference model. This is done in case when more than one well is located in one discretized grid or are located very close to each other. This reduces the well number at Chakratirtha water field to eleven and in Balia Panda water field to three. In addition, wells within the three grid from the boundary are not considered because; pumping from them will have a negligible effect on the aquifer. Therefore, final well count for finite difference model the Puri city aquifer is 17 . Among 17 wells, 11 in Chakratirtha water field, 3 in Balia Panda water field and 4 wells spread across the field (figure-6).

Initial water table condition is interpolated using Arc GIS from water table information collected at 22 well locations. The details of the hydrogeological parameters of the Puri coastal aquifer are listed in the table-3. Vijay et al. (2011b) reported that total pumping from the aquifer is $20.5 \times 10^{3} \mathrm{~m}^{3} /$ day from 36 pumping wells. Since the pumping from each well is not reported therefore, the pumping is adjusted to calibrate the head values. Pre and post monsoon water table information of 13 well locations are used to calibrate the model. The calibration head interval is $1 \mathrm{~m}$ and confidence level is $95 \%$. The calibration results for the groundwater flow model are represented by box plots (Figures 6). The absolute difference between the estimated and observed heads was well within the appropriate target interval, as indicated by the green box plots. Similarly, a yellow box plot indicates a small over/under estimation of the heads, with the absolute difference between the estimated and observed heads being somewhat outside the target interval. Larger estimate errors and poor calibration at such places are indicated by the red colour on the box-plot.

Table 3: Hydraulic properties of flow and transport model used in coastal aquifer of Puri city

\begin{tabular}{|l|l|} 
Parameter & Value \\
Area of the aquifer & $15.25 \mathrm{~km}^{2}$ \\
Grid dimension $(\Delta \mathrm{x}, \Delta \mathrm{y})$ & $30 \mathrm{~m} \times 30 \mathrm{~m}$ \\
Hydraulic conductivity & $19 \mathrm{~m}$ \\
Specific Storage & $2.9 \times 10^{-3} \mathrm{~m}^{-1}$ \\
Specific Yield & 0.3 \\
Recharge rate & $0.000222 \mathrm{~m} /$ day \\
Salt concentration in seawater & $35 \mathrm{~kg} / \mathrm{m}^{3}$ \\
Longitudinal dispersivity $\left(\alpha_{t}\right)$ & $14 \mathrm{~m}$ \\
$\alpha_{h} / \alpha_{t}$ and $\alpha_{v} / \alpha_{t}$ & 1 \\
Study period length & 30 years 9 months \\
\hline
\end{tabular}




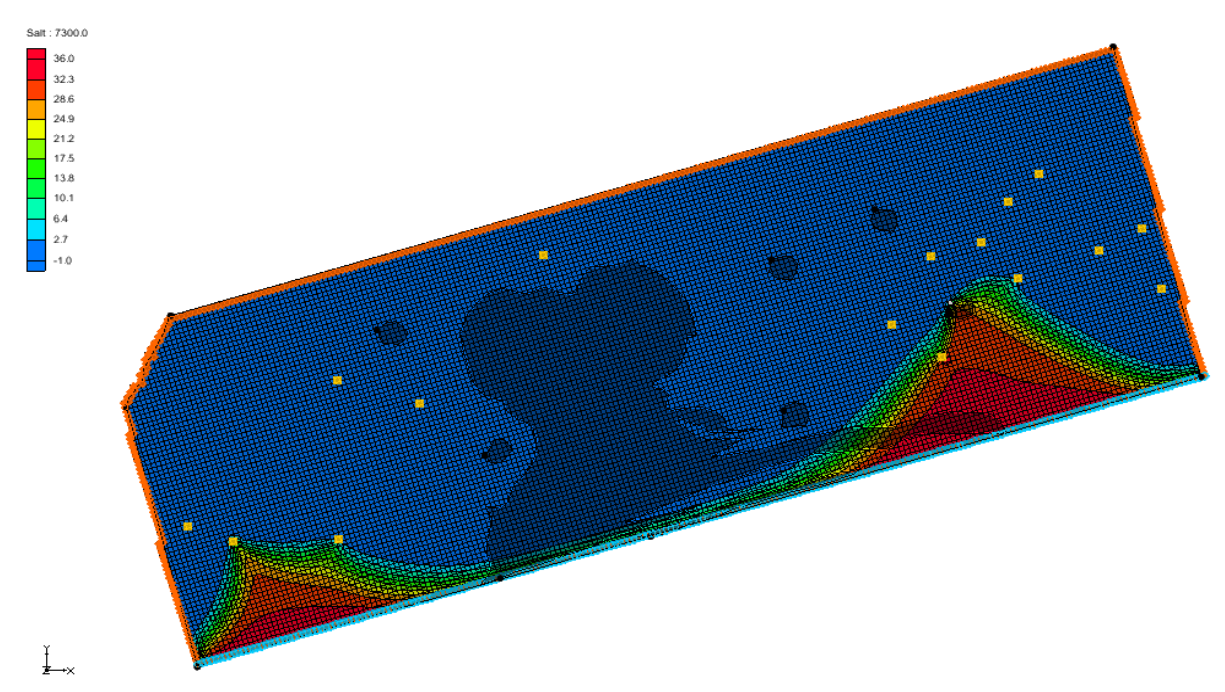

Figure 7: Salt concentration profile for coastal aquifer of Puri city

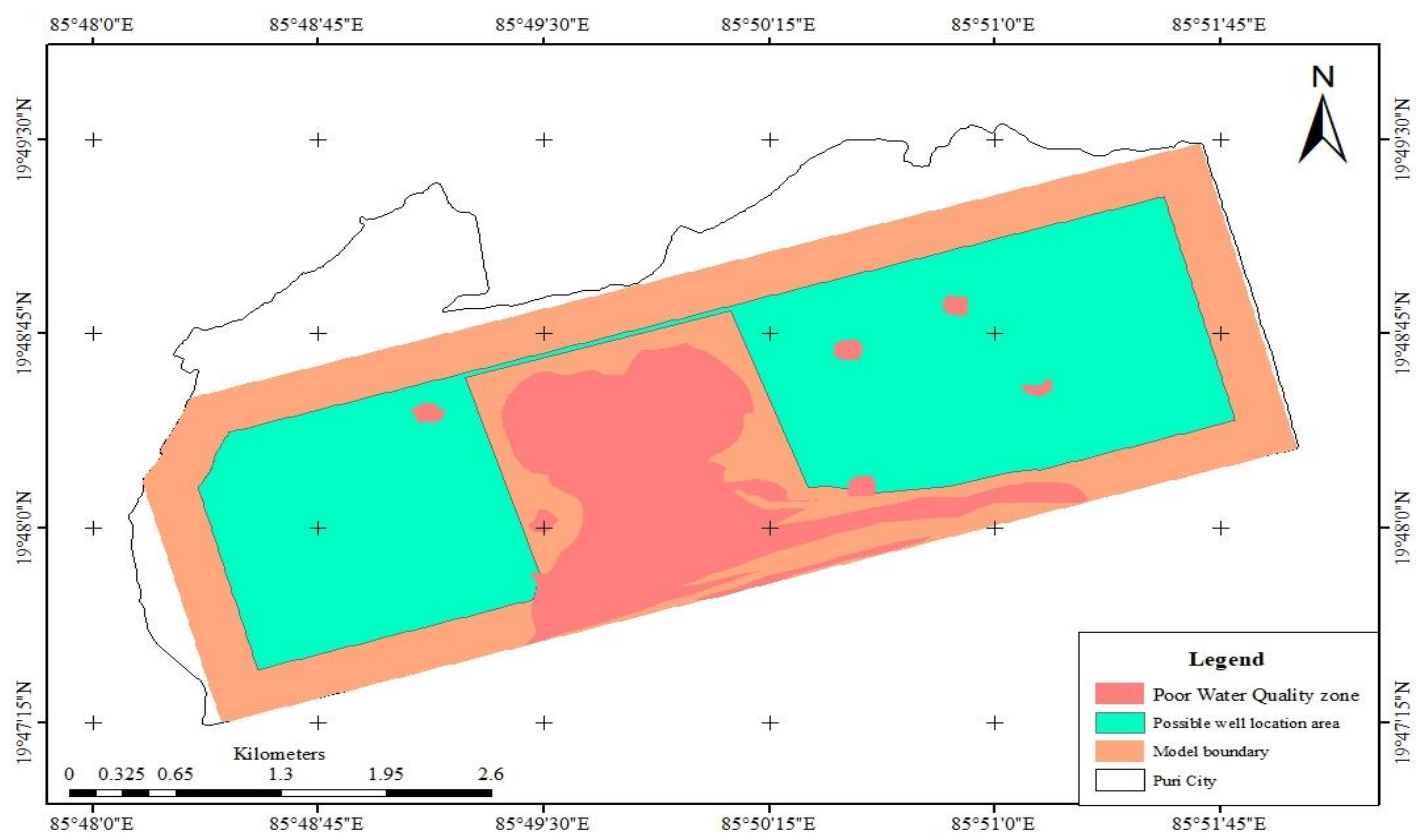

Figure 8: Possible well location of Puri city

Since no information is available for the initial position of the saltwater-freshwater front, therefore, modified Ghyben-Herzberg ratio (Dey and Prakash 2019a) is used to extrapolate the initial saltwater-freshwater front. The calibrated model is run for 30 years with the current rate of pumping to visualize the impact of saltwater intrusion in the Puri coastal aquifer. It can be clearly seen that at current rate of pumping there would be saltwater intrusion by year 2037 and some of the existing wells will be rendered useless (figure-7). Hence, it is necessary to optimize the pumping as well as find optimal locations for new wells to be installed to augment the existing supply of freshwater to meet the increasing demand. The locations of the new wells to 
be installed is further constrained by an existing poor water quality zone due to pollution from anthropogenic sources (figure-8).

\subsection{Evaluation results and discussion}

The iterative process of pumping optimization followed by density ratio optimization is run 15 and 16 times for both the scenarios respectively, to find the optimal pumping well locations and pumping rates from the installed wells. Corresponding density ratio is also calculated that would reflect the effect of dispersion and diffusion in a sharp-interface simulation model, thereby giving a more realistic estimate of the actual scenario without causing saltwater intrusion. The performance evaluation results of the optimal pumping value and the corresponding density ratio is presented in figure-9. It is observed that after eight iterations for scenario 1 and seven iterations for scenario 2 , there is no significant change in values of total

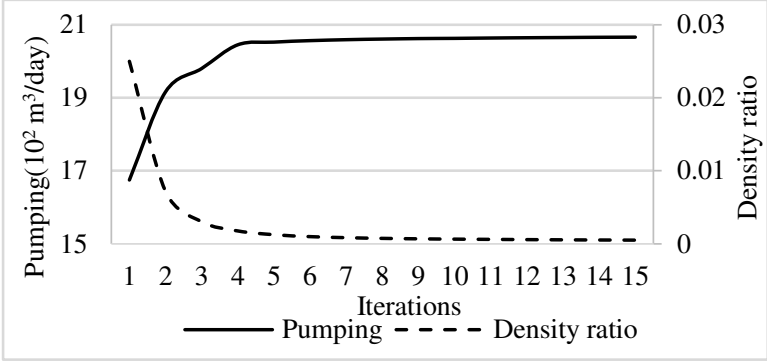

(a) Scenario-1

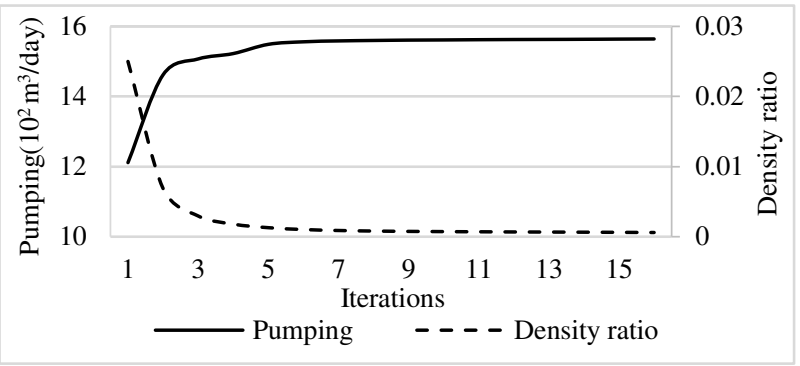

(b) Scenario-2

Figure 9: Plot of total pumping and density ratio for hypothetical scenario

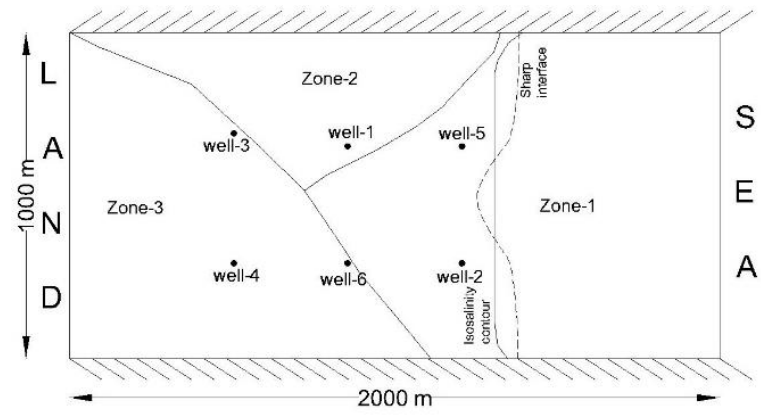

(a) Scenario-1

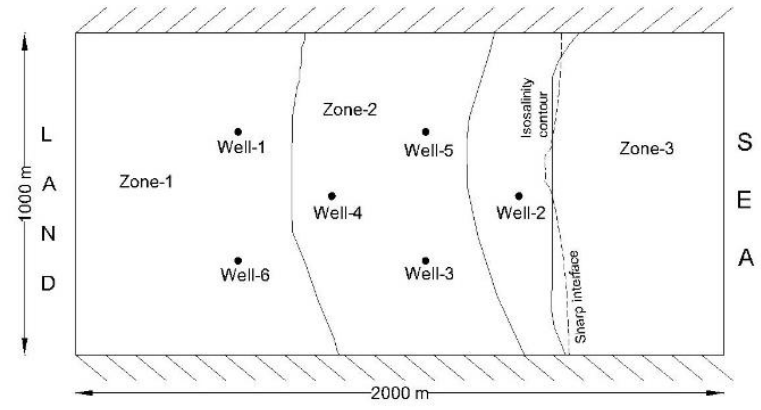

(b) Scenario - 2

Figure 10: Final well locations for hypothetical study scenarios

daily pumping and density ratio. The maximum total pumping for scenario 1 at eighth iteration was $2060.22 \mathrm{~m}^{3} /$ day and for scenario 2 the maximum total pumping after seventh iteration was $1560.88 \mathrm{~m}^{3} /$ day. The maximum total pumping in case of scenario 1 is more than scenario 2 . This could be explained by the locations of the pumping wells. Since the location of the pumping wells are not the same in both the cases, therefore, the maximum total pumping also varies. The methodology finds different locations in of wells in both the scenarios because of the different hydraulic conductivity in different zones of the study area. Optimized locations of each well, isosalinity contour corresponding to a salinity level of $5 \mathrm{~kg} / \mathrm{m}^{3}$ salt concentration, and toe of sharp-interface is plotted in the figure-10. It is evident from the figure that the optimal locations of the wells found by the methodology satisfies the required criteria of minimum distance for each other i.e. $350 \mathrm{~m}$ and a minimum distance of $350 \mathrm{~m}$ from the boundary. This ensures that 
there is no interference between the cone of influence of one well with the other and the wells can be pumped to its full potential without causing saltwater intrusion. The toe location from the sharp-interface is well in agreement with the corresponding isosalinity contour obtained from SEAWAT model. This shows that by optimizing the density ratio can improve the accuracy of prediction of the saltwater-freshwater front in a sharp-interface model without compromising the

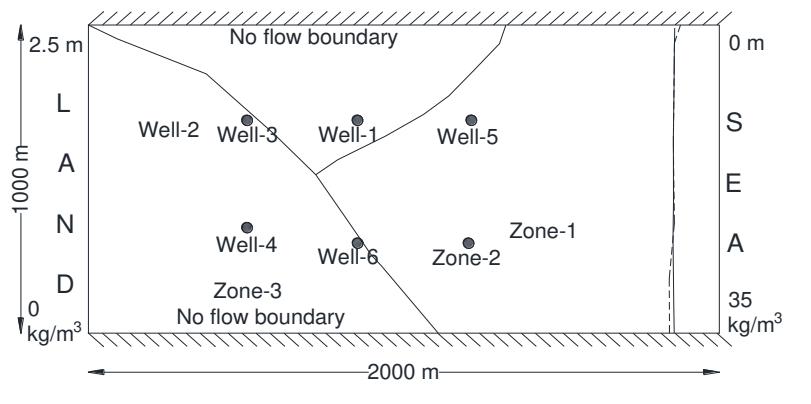

(a) Iteration-1

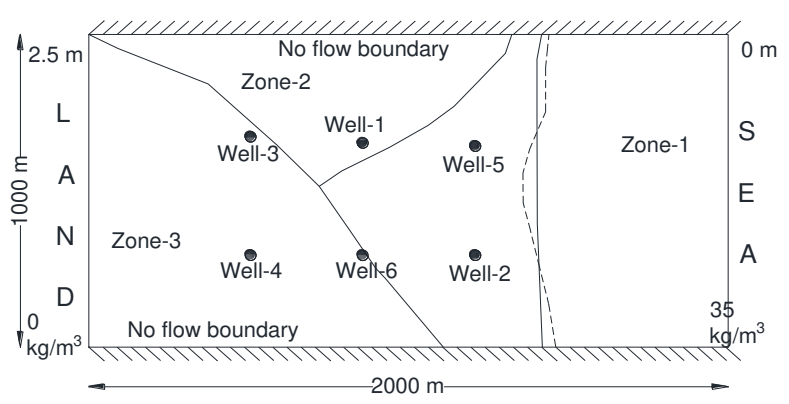

(c) Iteration-5

- Well Locations

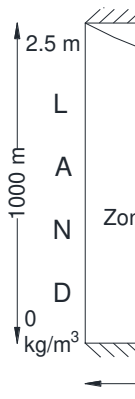

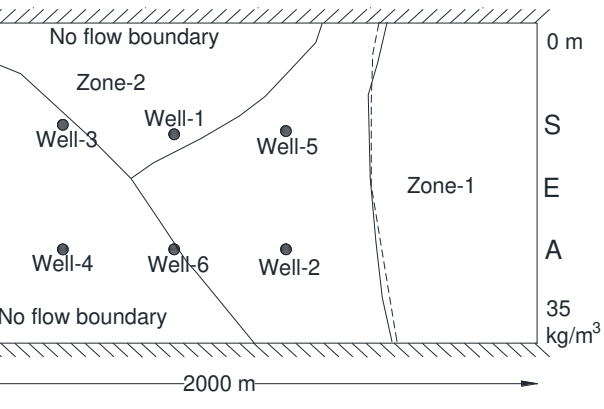

(b) Iteration-3

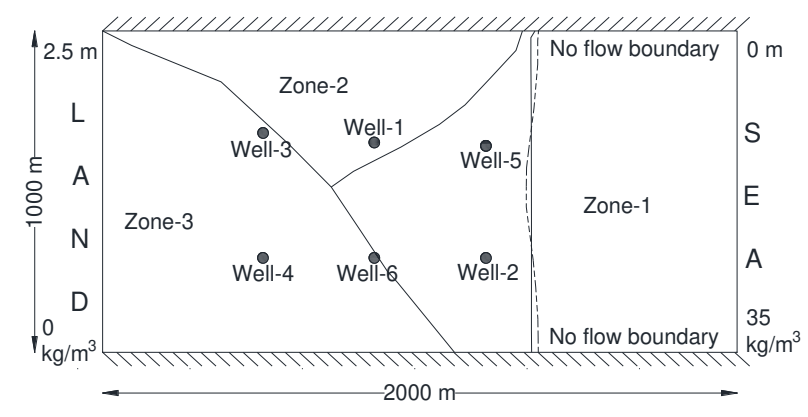

(d) Iteration-7

Sharp interface

Figure 11: Identified pumping well locations after intermediated iterations for scenario-1 efficiency. All the intermediate results of pumping at the end of selected iterations is shown in

Table 4: Pumping $\left(\mathrm{m}^{3} /\right.$ day $)$ from wells in hypothetical scenario-1

\begin{tabular}{lllllllll}
\hline & Well-1 & Well-2 & Well-3 & Well-4 & Well-5 & Well-6 & Total Pumping \\
Iteration-1 & 337.555 & 33.9704 & 499.855 & 500.000 & 45.4905 & 499.492 & 1916.362 \\
teration-3 & 499.451 & 16.0452 & 500.000 & 500.000 & 29.7311 & 499.998 & 2045.224 \\
Iteration-5 & 500.000 & 18.4212 & 499.999 & 500.000 & 38.1962 & 499.997 & 2056.613 \\
Iteration-7 & 499.999 & 20.2994 & 499.997 & 499.998 & 40.6541 & 499.998 & 2060.945 \\
\hline
\end{tabular}

table 4 and 5. Results of pumping well location optimization for iteration 1, 3, 5, 7 of scenario 1

Table 5: Pumping $\left(\mathrm{m}^{3} /\right.$ day $)$ from wells in hypothetical scenario-2

\begin{tabular}{llllllll}
\hline & Well-1 & Well-2 & Well-3 & Well-4 & Well-5 & Well-6 & Total Pumping \\
Iteration-1 & 499.987 & 10.105 & 15.528 & 425.677 & 10.535 & 499.945 & 1461.778 \\
Iteration-4 & 499.996 & 14.749 & 14.610 & 499.999 & 19.518 & 499.996 & 1548.869 \\
Iteration-6 & 499.996 & 10.035 & 20.346 & 499.999 & 28.273 & 499.990 & 1558.640 \\
Iteration-8 & 499.987 & 10.519 & 21.880 & 499.996 & 28.504 & 499.993 & 1560.880 \\
\hline
\end{tabular}


and iteration 2, 4, 6, and 8 of scenario 2 is presented in figure 11 and figure 12, respectively.

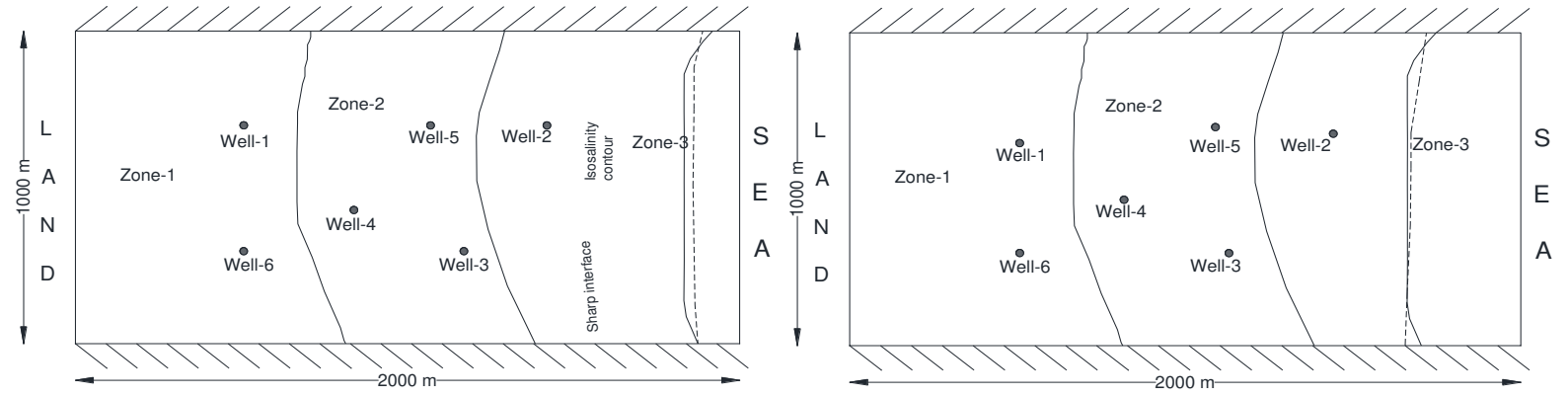

(a) Iteration-2

(b) Iteration-4

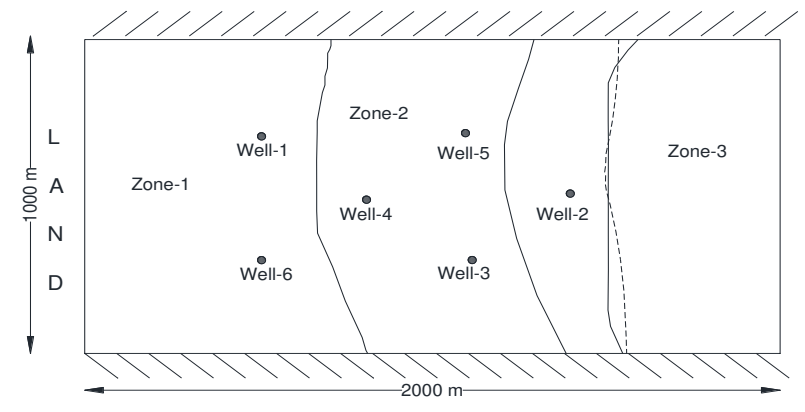

(c) Iteration-6

- Well Locations

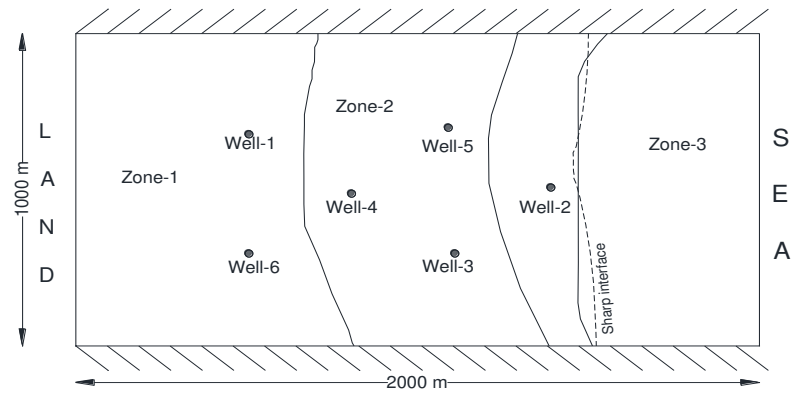

(d) Iteration-8 Sharp interface

Figure 12: Identified pumping well locations after intermediated iterations for scenario-2

\subsection{Evaluation results for coastal aquifer of Puri}

Outcome of pumping optimization and the corresponding density ratio for every iteration is shown in figure-13. It is noted that maximum pumping is achieved after four iterations with a maximum total pumping of $57.3 \times 10^{3} \mathrm{~m}^{3} /$ day and corresponding density ratio was 0.000992. The iterative process is run for ten iteration to ensure that the optimization does not converge to a local optima giving suboptimal

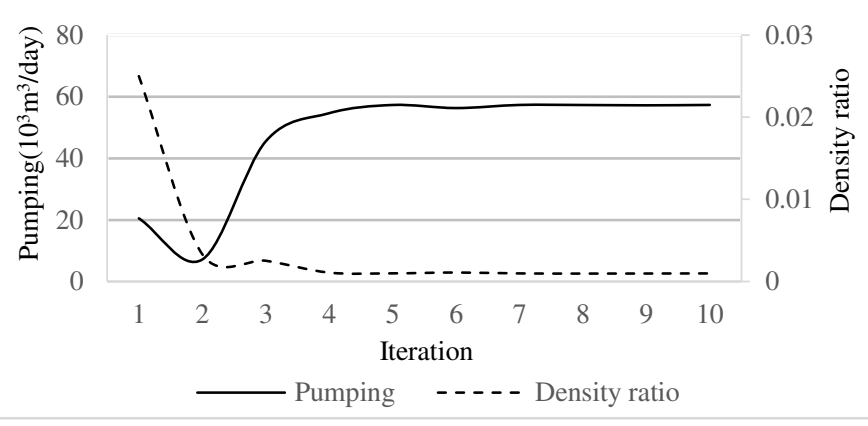

Figure 13: Plot of total pumping and density ratio for each iteration outcome. The maximum total pumping and density ratio did not show much significant change in further iterations and was stable up to the 10 iterations. Results obtained from this method shows that by optimally orienting the well locations the total freshwater extraction can be increased almost 3 times of the current extraction rate $\left(20.5 \times 10^{3} \mathrm{~m}^{3} /\right.$ day $)$. The final well locations, location of toe of sharp-interface and isosalinity contour are plotted in the figure13. It is clearly evident from the figure 14 that none of the wells located by this methodology has any saltwater intrusion. Toe location from the sharp-interface is found to be in close agreement with 
the isosalinity contour from SEAWAT. The well locations found by this methodology ensures that there is a minimum distance of $750 \mathrm{~m}$ between any two wells and a minimum of $300 \mathrm{~m}$ from the boundary of the study area. The methodology also ensures that the extraction wells are such positioned that they maintain a safe distance of $90 \mathrm{~m}$ from the poor quality zone.

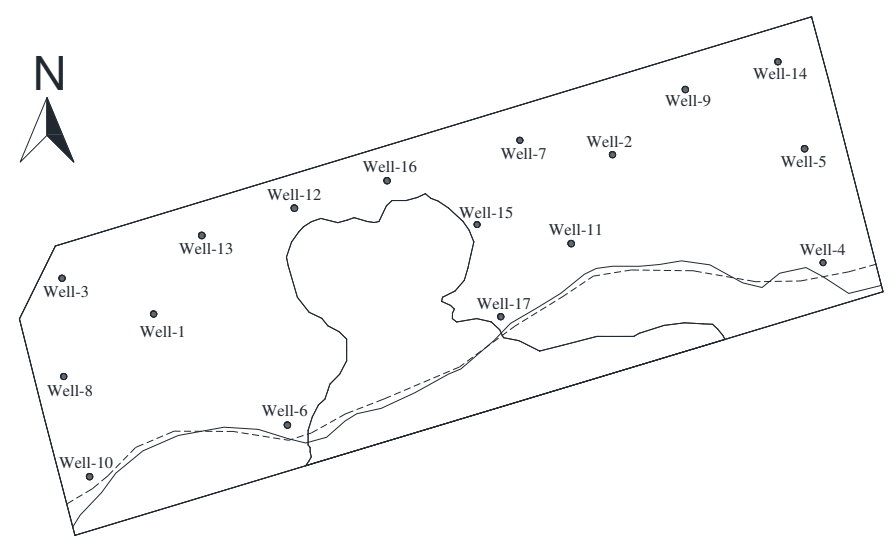

Figure 14: Final well locations and location of the interface for coastal aquifer of Puri

Wells no i.e. well-10, well-6, well -15, well-17 and well- 4 as seen in figure 14 are either

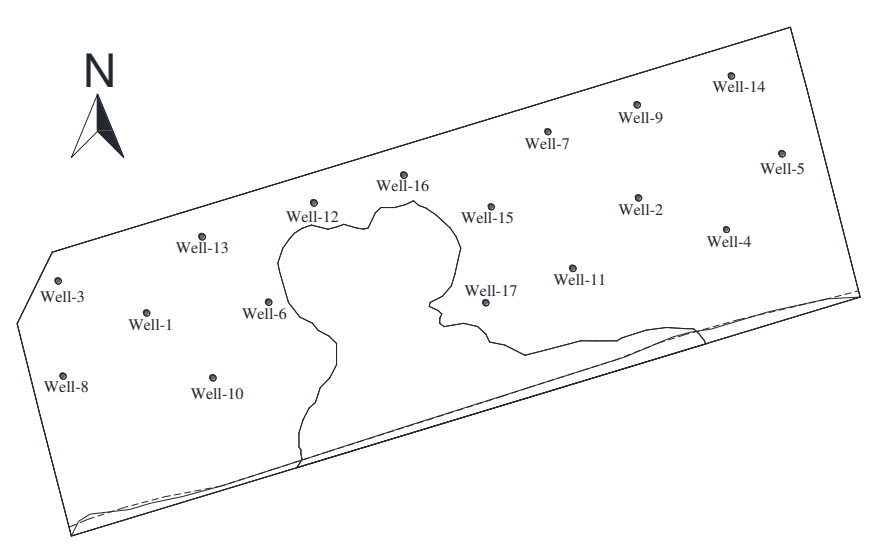

(a) Iteration-1

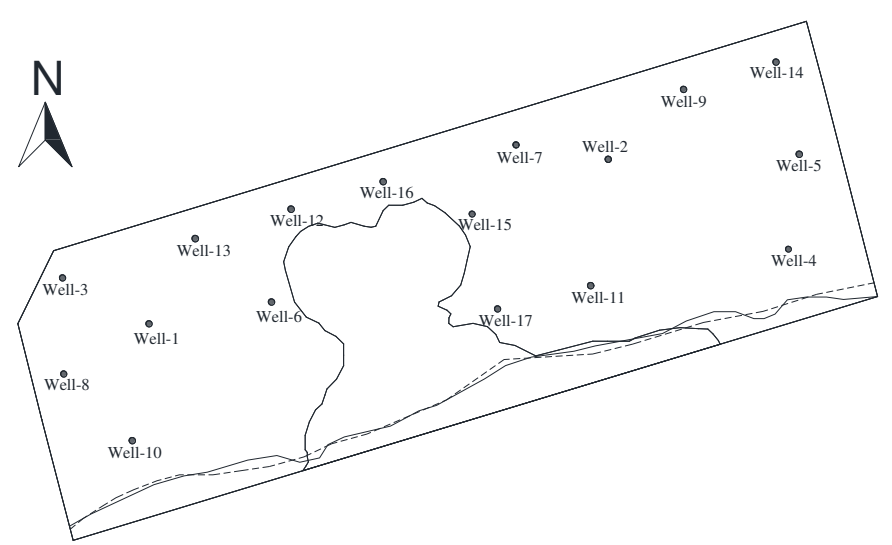

(b) Iteration-2

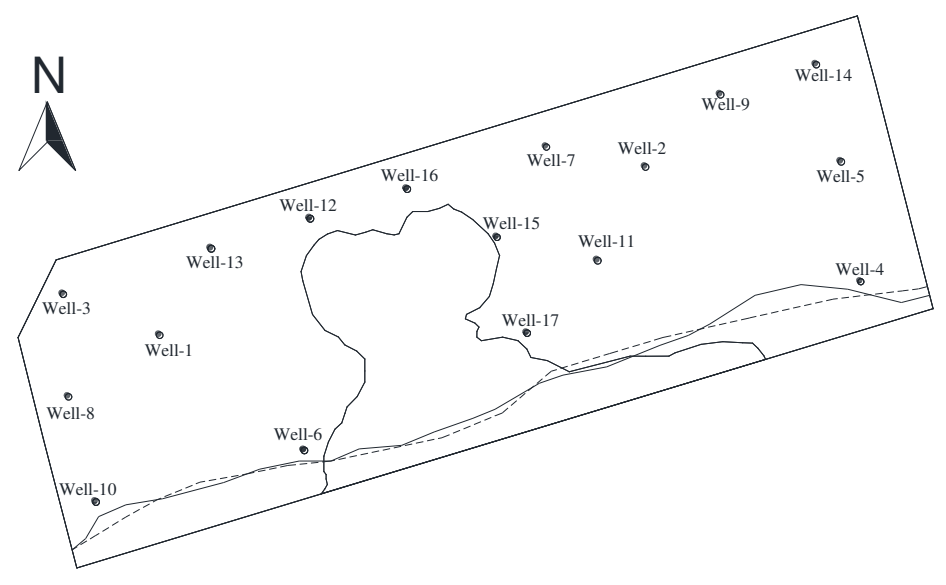

(c) Iteration-4

Figure 15: Location of wells and sharp interface at intermediate iteration for Puri coastal aquifer 
close to the poor water quality zone or the saltwater freshwater interface. Therefore, the respective distance of these wells is from interface or the boundary of the poor water quality zone is calculated (Table 6). The calculated distances show that all the wells are safely located. The intermediate results of well locations for aquifer is shown in figure 15

Table 6 : Location of critical wells

\begin{tabular}{lllll}
\hline Name of well & Critical factor & distance & Safe distance & Comment \\
Well - 6 & Sharp-interface & $155.36 \mathrm{~m}$ & $90 \mathrm{~m}$ & Safe \\
& Sharp-interface and poor & $90.01 \mathrm{~m}$ and & $90 \mathrm{~m}$ & Safe \\
Well - 12 & Poor quality area & $180.3 \mathrm{~m}$ & & \\
Well - 16 & Poor water quality area & $160.3 \mathrm{~m}$ & $90 \mathrm{~m}$ & Safe \\
Well - 15 & Poor water quality area & $150.23 \mathrm{~m}$ & $90 \mathrm{~m}$ & Safe \\
Well - 17 & Sharp-interface and poor & $90.2 \mathrm{~m}$ & $90 \mathrm{~m}$ & Safe \\
& Water quality area & m & Safe \\
Well - 4 & Sharp-interface & $150.17 \mathrm{~m}$ & $90 \mathrm{~m}$ & Safe \\
\hline
\end{tabular}

Table 7 : Pumping rate at each iterations

\begin{tabular}{lrrrrr}
\hline Well-1 & & & & & \\
Well-2 & 50.00 & 52.20 & 62.20 & 68.36 & 76.94 \\
Well-3 & 50.00 & 293.29 & 100.29 & 90.96 & 81.77 \\
Well-4 & 1908.37 & 5500.00 & 5500.00 & 5500.00 & 5500.00 \\
Well-5 & 50.00 & 250.04 & 3000.04 & 5500.00 & 5500.00 \\
Well-6 & 152.54 & 5500.00 & 5500.00 & 5500.00 & 5500.00 \\
Well-7 & 50.00 & 598.88 & 501.88 & 430.69 & 442.11 \\
Well-8 & 362.09 & 5499.96 & 5499.96 & 5500.00 & 5500.00 \\
Well-9 & 50.00 & 3439.69 & 3439.69 & 3510.69 & 3518.80 \\
Well-10 & 730.24 & 4184.55 & 5500.55 & 5500.00 & 5500.00 \\
Well-11 & 50.00 & 50.00 & 200.00 & 300.69 & 345.12 \\
Well-12 & 50.00 & 54.67 & 80.67 & 120.70 & 152.00 \\
Well-13 & 50.01 & 5500.00 & 5500.00 & 5500.00 & 5500.00 \\
Well-14 & 50.00 & 2854.04 & 3000.04 & 5500.00 & 5500.00 \\
Well-15 & 931.17 & 5500.00 & 5500.00 & 5500.00 & 5500.00 \\
Well-16 & 50.00 & 505.22 & 450.22 & 451.69 & 455.72 \\
Well-17 & 2508.33 & 5499.89 & 5499.89 & 5500.00 & 5500.00 \\
Total Pumping & 50.00 & 215.19 & 215.19 & 70.96 & 58.38 \\
\hline
\end{tabular}

\section{Conclusions}

Sharp-interface linked to SA optimization and density dependent model linked to PSO is coupled to develop this methodology. The developed methodology performs satisfactorily in optimizing pumping well locations and maximum total pumping from a coastal aquifer without causing saltwater intrusion. The coupled approach reduces the computational effort by 
eliminating the need to run SEAWAT model to evaluate each candidate solution. The developed methodology clearly establishes that location of the pumping wells have a significant role in deciding the maximum total pumping from a coastal aquifer. It is also seen that the locations of the production wells are sensitive to hydrogeological settings and impact the total pumping from the aquifer.

This can be concluded that, the developed methodology can be a viable option in managing coastal aquifer with greater accuracy compared to linked simulation optimization with sharp-interface model for limited computational budget.

Performance evaluation results show that the method can simultaneously optimize both the locations of the pumping wells as well as pumping rates as tool for managing saltwater intrusion. Constrains of location in design of any well field is quite common and often restrictive in terms of placement of production wells. This developed methodology is robust to handle such restrictive constraints and still find the optimal pumping rates to manage saltwater intrusion. While taking costal aquifer of Puri city as a proof of concept, it is clear that this methodology can potentially increase the total freshwater pumping by almost 3 times the existing pumping without causing saltwater intrusion by optimally choosing the well locations. The methodology in its current form can be directly applied for new well fields design for sustainable freshwater extraction from coastal aquifer. The method can also be applied to scenarios where the existing freshwater extraction is to be increased by augmenting new wells in coastal aquifer without causing salt water intrusion. The developed methodology can bolster the freshwater supply in meeting the future demands without causing saltwater intrusion.

\section{References}

Abarca E, Carrera J, Sánchez-Vila X, Dentz M (2007) Anisotropic dispersive Henry problem Advances in Water Resources 30:913-926

Abd-Elaty I, Javadi AA, Abd-Elhamid H (2021) Management of saltwater intrusion in coastal aquifers using different wells systems: a case study of the Nile Delta aquifer in Egypt Hydrogeology Journal:1-17

Abd-Elhamid HF, Javadi AA (2011) A cost-effective method to control seawater intrusion in coastal aquifers Water resources management 25:2755-2780

Ahmadi H, Kilanehei F, Nazari-Sharabian M (2021) Impact of Pumping Rate on Contaminant Transport in Groundwater-A Numerical Study Hydrology 8:103

Bhattacharjya RK, Datta B (2005) Optimal management of coastal aquifers using linked simulation optimization approach Water resources management 19:295-320

Bhattacharjya RK, Datta B (2009) ANN-GA-based model for multiple objective management of coastal aquifers Journal of Water Resources Planning and Management 135:314-322

Cheng AD, Halhal D, Naji A, Ouazar D (2000) Pumping optimization in saltwater-intruded coastal aquifers Water Resources Research 36:2155-2165

Christelis V, Mantoglou A (2016) Coastal aquifer management based on the joint use of densitydependent and sharp-interface models Water resources management 30:861-876

Culver TB, Shoemaker CA (1993) Optimal control for groundwater remediation by differential dynamic programming with Quasi-Newton approximations Water Resources Research 29:823-831 
Das A, Datta B (1999) Development of management models for sustainable use of coastal aquifers Journal of irrigation and drainage engineering 125:112-121

Dausman AM, Langevin C, Bakker M, Schaars F (2010) A comparison between SWI and SEAWAT-the importance of dispersion, inversion and vertical anisotropy Proceedings of SWIM 21:271-274

Dey S, Prakash O (2019a) Accurate estimation of initial saltwater-freshwater interface for simulating saltwater intrusion using numerical methods

Dey S, Prakash O (2019b) Management of saltwater intrusion in coastal aquifers: An overview of recent advances. In: Raj Mohan Singh PS, and Prabhakar Shukla (ed) Environmental Processes and Management, vol 1. Springer Nature,

Dey S, Prakash O (2020) Managing saltwater intrusion using conjugate sharp-interface and density dependent models linked with pumping optimization Groundwater for Sustainable Development: 100446

Dhar A, Datta B (2009a) Saltwater intrusion management of coastal aquifers. I: Linked simulation-optimization Journal of Hydrologic Engineering 14:1263-1272

Dhar A, Datta B (2009b) Saltwater intrusion management of coastal aquifers. II: Operation uncertainty and monitoring Journal of Hydrologic Engineering 14:1273-1282

Dokou Z, Karatzas GP (2012) Saltwater intrusion estimation in a karstified coastal system using density-dependent modelling and comparison with the sharp-interface approach Hydrological Sciences Journal 57:985-999

Eberhart R, Kennedy J A new optimizer using particle swarm theory. In: Micro Machine and Human Science, 1995. MHS'95., Proceedings of the Sixth International Symposium on, 1995. IEEE, pp 39-43

Frind EO (1982) Seawater intrusion in continuous coastal aquifer-aquitard systems Advances in water Resources 5:89-97

Goffe WL (1996) SIMANN: A global optimization algorithm using simulated annealing Studies in Nonlinear Dynamics \& Econometrics 1

Guan J, Aral M (1999) Optimal remediation with well locations and pumping rates selected as continuous decision variables Journal of Hydrology 221:20-42

Guo W, Langevin CD (2002) User's guide to SEAWAT; a computer program for simulation of three-dimensional variable-density ground-water flow.

Harbaugh AW, Banta ER, Hill MC, McDonald MG (2000) MODFLOW-2000, The U. S. Geological Survey Modular Ground-Water Model-User Guide to Modularization Concepts and the Ground-Water Flow Process Open-file Report U S Geological Survey: 134

Kirkpatrick S (1984) Optimization by simulated annealing: Quantitative studies Journal of statistical physics 34:975-986

Kourakos G, Mantoglou A (2009) Pumping optimization of coastal aquifers based on evolutionary algorithms and surrogate modular neural network models Advances in Water Resources 32:507-521

Mantoglou A (2003) Pumping management of coastal aquifers using analytical models of saltwater intrusion Water resources research 39

Mantoglou A, Papantoniou M (2008) Optimal design of pumping networks in coastal aquifers using sharp-interface models Journal of Hydrology 361:52-63 
Mantoglou A, Papantoniou M, Giannoulopoulos P (2004) Management of coastal aquifers based on nonlinear optimization and evolutionary algorithms Journal of Hydrology 297:209228

Park C-H, Aral MM (2004) Multi-objective optimization of pumping rates and well placement in coastal aquifers Journal of Hydrology 290:80-99

Poli R, Kennedy J, Blackwell T (2007) Particle swarm optimization Swarm intelligence 1:33-57

Pool M, Carrera J (2011) A correction factor to account for mixing in Ghyben-Herzberg and critical pumping rate approximations of seawater intrusion in coastal aquifers Water Resources Research 47

Rao S, Thandaveswara B, Bhallamudi SM, Srinivasulu V (2003) Optimal groundwater management in deltaic regions using simulated annealing and neural networks Water Resources Management 17:409-428

Roy DK, Datta B (2018) A surrogate based multi-objective management model to control saltwater intrusion in multi-layered coastal aquifer systems Civil Engineering and Environmental Systems:1-26

Shi Y, Eberhart R A modified particle swarm optimizer. In: Evolutionary Computation Proceedings, 1998. IEEE World Congress on Computational Intelligence., The 1998 IEEE International Conference on, 1998. IEEE, pp 69-73

Sreekanth J, Datta B (2010) Multi-objective management of saltwater intrusion in coastal aquifers using genetic programming and modular neural network based surrogate models Journal of Hydrology 393:245-256

Sreekanth J, Datta B (2011) Comparative evaluation of genetic programming and neural network as potential surrogate models for coastal aquifer management Water resources management 25:3201-3218

Sreekanth J, Datta B (2014) Stochastic and robust multi-objective optimal management of pumping from coastal aquifers under parameter uncertainty Water resources management 28:2005-2019

Strack O (1976) A single-potential solution for regional interface problems in coastal aquifers Water Resources Research 12:1165-1174

Todd DK (1959) Ground water hydrology. John Wiley and Sons, Inc, New York,

Vijay R, Khobragade P, Mohapatra P (2011a) Assessment of groundwater quality in Puri City, India: an impact of anthropogenic activities Environmental monitoring and assessment 177:409-418

Vijay R, Mohapatra P (2016) Hydrodynamic assessment of coastal aquifer against saltwater intrusion for city water supply of Puri, India Environmental Earth Sciences 75:588

Vijay R, Samal D, Mohapatra PK (2011b) GIS based identification and assessment of groundwater quality potential zones in Puri city, India Journal of Water Resource and Protection 3:440

Werner AD et al. (2013) Seawater intrusion processes, investigation and management: recent advances and future challenges Advances in Water Resources 51:3-26

Willis R, Finney BA (1988) Planning model for optimal control of saltwater intrusion Journal of Water Resources Planning and Management 114:163-178

Zheng C, Wang PP (1999) MT3DMS: a modular three-dimensional multispecies transport model for simulation of advection, dispersion, and chemical reactions of contaminants in groundwater systems; documentation and user's guide. Alabama Univ University, 